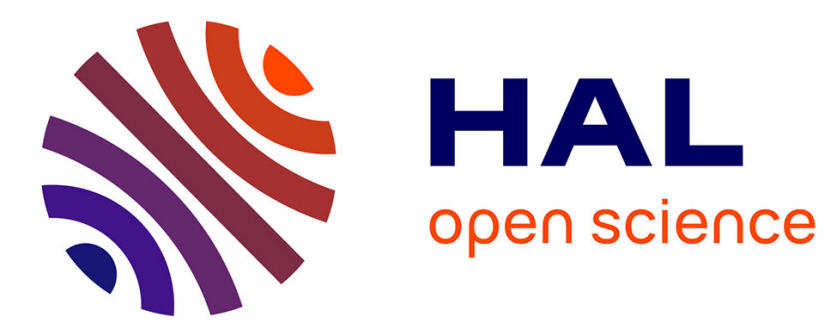

\title{
CEMS STUDY OF Fe60Al40 THIN FILMS
}

\author{
A. Fnidiki, J. Eymery
}

\section{To cite this version:}

A. Fnidiki, J. Eymery. CEMS STUDY OF Fe60Al40 THIN FILMS. Journal de Physique Colloques, 1988, 49 (C8), pp.C8-1735-C8-1736. 10.1051/jphyscol:19888789 . jpa-00229042

\section{HAL Id: jpa-00229042 https://hal.science/jpa-00229042}

Submitted on 1 Jan 1988

HAL is a multi-disciplinary open access archive for the deposit and dissemination of scientific research documents, whether they are published or not. The documents may come from teaching and research institutions in France or abroad, or from public or private research centers.
L'archive ouverte pluridisciplinaire HAL, est destinée au dépôt et à la diffusion de documents scientifiques de niveau recherche, publiés ou non, émanant des établissements d'enseignement et de recherche français ou étrangers, des laboratoires publics ou privés. 


\title{
CEMS STUDY OF $\mathrm{Fe}_{60} \mathrm{Al}_{40}$ THIN FILMS
}

\author{
A. Fnidiki and J. P. Eymery \\ Laboratoire de Métallurgie Physique, U.A.131 du C.N.R.S., 40 avènue du Recteur Pineau F.86022 Poitiers \\ Cedex, France
}

\begin{abstract}
The coevaporation technique offers the possibility to prepare $\mathrm{Fe}_{60} \mathrm{Al}_{40}$ thin films which behave ferromagnetically at $293 \mathrm{~K}$. They show nearly same magnetic properties as cold worked or ion-implanted bulk $\mathrm{Fe}_{60} \mathrm{Al}_{40} . \mathrm{On}$ the contrary, their behaviour strongly differs at higher temperatures so that the precipitation of iron rich phases is inferred from CEMS analysis.
\end{abstract}

In a recent paper [1], it has been shown that magnetic $\mathrm{Fe}_{60} \mathrm{Al}_{40}$ films could be prepared by coevaporation. This result is important because bulk $\mathrm{Fe}_{60} \mathrm{Al}_{40}$ having the $\mathrm{L} 20$ superstructure is paramagnetic at $293 \mathrm{~K}$ and previously it could be rendered ferromagnetic at this temperature only under certain conditions, namely after cold working [2] or ionimplantation [3]. These treatments were assumed to create atomic disorder so that a given $\mathrm{Fe}$ atom had a good probability to be surrounded by at least three or four Fe atoms which is necessary for him to bear magnetic moments. We describe here further results on the magnetic properties of coevaporated $\mathrm{Fe}_{60} \mathrm{Al}_{40}$ thin films $(200 \mathrm{~nm})$ deposited on a Si substrate. Special emphasis will be placed on the thermal behaviour of the films which showed striking features. The magnetic properties were chiefly evaluated with the Mössbauer effect working in scattering geometry (CEMS); additional informations were obtained with a polar Kerr effect measurement systems.

The films were deposited on a Si substrate by coevaporation. Two E-beams installed in a high vacuum chamber were used; the starting pressure was $1 \times 10^{-8}$ Torr and during deposition it was maintained at about $2-3 \times 10^{-8}$ Torr; 'the deposition rate of each element, typically $0.2-0.3 \mathrm{~mm} / \mathrm{s}$, and the thickness of the layer were monitored by two quartz oscillators. Concerning the CEMS technique, the $7.3 \mathrm{keV}$ conversion and $5.6 \mathrm{keV}$ Auger electron spectra were taken using a source of $50 \mathrm{mCi}{ }^{57} \mathrm{Co}$ in rhodium, a proportional counter with a $\mathrm{He}-5 \% \mathrm{CH}_{4}$ gas flow and a conventional Mössbauer spectrometer; the counter has been recently described in details in reference [4]. The analysis of the spectra was performed by summing a central Lorentzian line and a distribution of hyperfine fields (Window method [5]). The magnetization was determined using a polar Kerr effect measurement device, the laser of which had a wavelength of $632.8 \mathrm{~nm}$.

The $293 \mathrm{~K}$ electron spectrum of an as-coevaporated thin film is presented in figure 1a. The average hyperfine field $\vec{H}$ is found to be $218 \mathrm{kOe}$ while the percentage of magnetic iron is $74 \%$ (see Tab. I). These

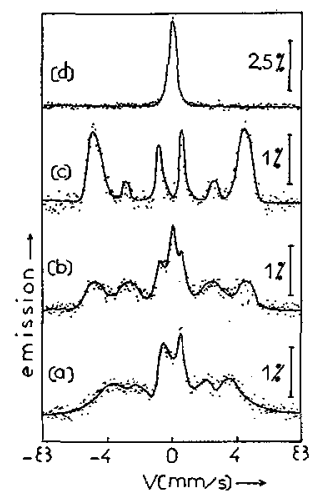

Fig. 1. - Room temperature CEM spectra: (a) ascoevaporated, (b) annealing temperature $=573 \mathrm{~K}$, (c) $773 \mathrm{~K}$, (d) $873 \mathrm{~K}$.

results are in good agreement with those determined on both implanted [3] and crushed [2] bulk samples. Figure 2 shows the variation in Kerr rotation angle $\theta_{\mathrm{K}}$ as a function of applied magnetic field. Saturation is reached for $\theta_{\mathrm{K}}=13^{\prime}$ and $4 \pi M=6.4 \mathrm{kOe}$; assuming a density of $6.02 \mathrm{~g} . \mathrm{cm}^{-3}$, the magnetic moment is found to be $\sigma=84.5 \mathrm{emu} / \mathrm{g}$, a result which is also in agreement with the value determined on implanted samples by ferromagnetic resonance [6]. From the above data it is quite satisfactory to note that the three kinds of sample preparation namely cold working, ion- implantation and coevaporation, lead to nearly same magnetic properties.

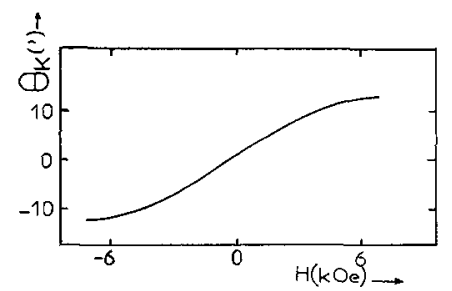

Fig. 2. - Kerr rotation angle versus magnetic field at 293 K. 
We report now the thermal behaviour of the films as determined by CEMS. The sample under study was annealed for one hour under a $10^{-6}$ Torr vacuum at the required temperature in the range $293-873 \mathrm{~K}$ and then the CEM spectrum was taken at $293 \mathrm{~K}$. The spectra are presented in figures $1 b, c, d$ while the corresponding Mössbauer parameters are listed in table I.

Table I. - Mössbauer parameters. Left and right sides correspond to field distribution and paramagnetic central line respectively: $\bar{H}=$ average hyperfine field, $\sigma_{H}=$ standard deviation, $b=$ relative intensity of lines 2 and $5, f_{\mathrm{f}}=$ ferromagnetic fraction, $I S=$ isomer shift with respect to $\alpha$-iron, $\Gamma=$ half line width. The large values of $\Gamma$ determined for spectra $1 a, b$ indicate the paramagnetic fraction is also distributed.

\begin{tabular}{|c|cccc|cc|}
\hline$T(\mathrm{~K})$ & $\begin{array}{c}\tilde{H} \\
(\mathrm{kOe})\end{array}$ & $\begin{array}{c}\sigma_{H} \\
(\mathrm{kOe})\end{array}$ & $b$ & $\begin{array}{c}f_{\mathrm{f}} \\
(\%)\end{array}$ & $\begin{array}{c}\text { IS } \\
(\mathrm{mm} / \mathrm{s})\end{array}$ & $\begin{array}{c}\Gamma \\
(\mathrm{mm} / \mathrm{s})\end{array}$ \\
\hline $\begin{array}{c}293 \\
\text { after 1 h } \\
\text { at } 573 \\
\text { after 1 h } \\
\text { at } 773 \\
\text { after 1 h } \\
\text { at 873 }\end{array}$ & 218 & 51 & 1.1 & 74 & 0.15 & 0.5 \\
\hline
\end{tabular}

First, we have to point out that the spectra unambiguously show a magnetic fraction $\left(f_{\mathrm{f}}\right)$ up to at least $773 \mathrm{~K}$; at this temperature $f_{\mathrm{f}}=100 \%$ so that no paramagnetic iron is remaining. A paramagnetic spectrum is only obtained after annealing at $873 \mathrm{~K}$; the most probable reason for this change is the diffusion of $\mathrm{Si}$ from the substrate iato the film. A strong difference then appears with respect to both cold worked and ion-implanted bulk $\mathrm{Fe}_{60} \mathrm{Al}_{40}$ for which the magnetic interactions disappeared at temperatures slightly higher than $293 \mathrm{~K} \mathrm{[7];} \mathrm{in} \mathrm{this} \mathrm{case,} \mathrm{L} 2_{0}$ atomic reordering was assumed to take place, thus leading to paramagnetic spectra. On the contrary, the hyperfine field of the coevaporated films increases with increasing temperature up to $301 \mathrm{kOe}$, a value slightly higher than that of $\mathrm{D}$ sites in ordered $\mathrm{Fe}_{3} \mathrm{Al}$, i.e. $290 \mathrm{kOe}$. This variation in field indicates the presence of iron-rich domains, the relative abundance of which increases up to $100 \%$ at $773 \mathrm{~K}$. Atomic ordering of L2o type, if any exists, may contribute to the paramagnetic fraction but from the above result it is clear that the basic phenomenon is rather new phase precipitation than $\mathrm{L} 22_{0}$ ordering. This behaviour is first surprising; however, it is to be recalled that the coevaporation technique leads to metastable random alloys exhibiting local fluctuations of composition because the evaporation rate from each source cannot be maintained rigorously constant. In our case, the Mössbauer spectra suggest that at $773 \mathrm{~K}$, significant atomic motion becomes possible enabling the transformation of metastable $\mathrm{Fe}_{60} \mathrm{Al}_{40}$ into one or several phase(s) of higher stability close to $\mathrm{Fe}_{3} \mathrm{Al}$ and $\alpha$-Fe. Finally it is noteworthy that Godbole et al. [8] have already observed same trend in ion-beam-mixed $\mathrm{Fe}_{55} \mathrm{Al}_{45}$ samples.

As a conclusion we have prepared thin films of $\mathrm{Fe}_{60} \mathrm{Al}_{40}$ by coevaporation, the magnetic properties of which at room temperature appear to be nearly the same as those of bulk material chemically disordered either by cold working or by ion-implantation. However, at temperatures higher than $293 \mathrm{~K}$, i.e. in the 573-773 $\mathrm{K}$ range, the films show a tendency towards new iron rich phase precipitation instead of $\mathrm{L} 20$ ordering as expected from the bulk behaviour.

[1] Fnidiki, A., Eymery, J. P. and Junqua, N., Solid State Commun. 63 (1987) 549.

[2] Huffman, G. P. and Fisher, R. M., J. Appl. Phys. 38 (1967) 735.

[3] Fnidiki, A., Eymery, J. P. and Delafond, J., J. Magn. Magn. Mater. 40 (1983) 130.

[4] Bodin, D. and Eymery, J. P., Nucl. Instrum. Methods $B 16$ (1986) 424 .

[5] Window, B., J. Phys. E 4 (1971) 401.

[6] Krishnan, R., Suran, G., Eymery, J. P., Rivière, J. P. and Fnidiki, A., Phys. Lett. A. 121 (1987) 43.

[7] Fnidiki, A., Bodin, D. and Eymery, J. P., -Hyp. Inter. 29 (1986) 1179.

[8] Godbole, V. P., Chaudhari, S. M., Ghaisas, S. V., Kanetkar, S. M. and Ogale, S. B., Phys. Rev. B 31 (1985) 5703. 